\title{
Evaluate the Effectiveness of Advertising on Customers' Willingness to Buy (Case Study: Goldiran Products Customers)
}

\author{
ASHTIANI Peyman Ghafari' ${ }^{29}$, BAHMANZADEH Fatemeh ${ }^{30}$
}

\begin{abstract}
This research had been done to evaluate the effectiveness of advertising on customers' willingness to buy. The aim of this research was applied and the method of data collection was descriptive and causal-effect. The statistical population of this research was customers of Goldiran products in Tehran who visited the company's representatives to buy. The sample size with the help of Cochran formula was 384 people and sampling method was random, stratified based on geographic area was calculated. Data gathering tool included two questionnaires by Jafari (1393) to measure advertising effectiveness and customers' willingness to buy and questionnaire by Boyle et al., (2013) to measure brand image and brand equity. The validity of these two questionnaires were confirmed by content and construct validity. As well as, reliability of 4 variables were obtained higher than 7/0 with the help of Cronbach's alpha coefficient. Data from distributing questionnaires were analyzed using LISREL software. For this purpose, using confirmatory factor analysis test, accuracy of measurement variables was confirmed. Then, it turned out through track analysis test that although brand equity was effective on the willingness of customers to buy, however it could not be reached through company's advertising. Also, although advertising caused brand image; however, the image had little effect on customers' willingness to buy company's products.
\end{abstract}

Keywords: Advertising Effectiveness, Customer Willingness to Buy, Brand Image, Brand Equity

JEL: D12, M31

UDK: 659.113.7

005.336.1

COBISS.SR-ID 253513228

\section{Introduction}

Nowadays, Customer's right to choose has had a significant increase due to increasing competition between the companies to discover, customer retention and ultimately profitability, (Coon et al., 2014). Therefore, customers are trying to obtain their needed information before buying in different ways from different companies and suppliers and comparing them to make the best choice. One of the most common ways to provide this information is advertising. "The purpose of advertising is communications tools that companies use to communicate with people who want to buy product or service" (Pita, Flavler, 2013). In other words, "propaganda is a tool to build a relationship with the customer to inform and influence their attitudes and behavior"

\footnotetext{
${ }^{29}$ Department of Management, Arak Branch, Islamic Azad University, Arak, Iran, pghafari@iau-arak.ac.ir

${ }^{30}$ Arak Branch, Islamic Azad University, Arak, Iran
} 
(Nikookar et al., 1388). On the other hand, although the advertising is mentioned as an investment, but there is no doubt that costs a fortune to the company; Therefore, advertisers and marketers are always interested in evaluating the effect of their advertising on end customers.

"In fact, they are increasingly seeking to prove the effectiveness of their ads" (Morley, 2007).

Because, there is a variety of devices including TV, radio, internet commercials, social networks, install banners in the city, sponsor sports teams and the company needs to recognize that how much profit gain when investment on advertising (Ghouchani et al., 1392). In general, advertisers have defined the advertising effectiveness "to deliver the company's messages to customers with the objectives of notification, reminders, stimulate purchases, competition and respond to competitors" (Campbell, Wright, 2008). On the other hand, researchers believe that despite the importance of advertising on the increase of sale, evaluating it effectiveness is not simply take place. The reason is that advertising is a complex process and ad performance is completely dependent on customer response (Buil et al., 2013). However, some other researchers believe that ways of measuring the effectiveness of advertising, including direct and medium scales (Ghouchani et al., 1392). On the one hand, direct scales, tests and examines the actual behavior of watching ads and assuming the hierarchy of effects, assess the impact of an ad is relevant with the attention or gain knowledge of the advertiser message and on the other hand, intermediate scale evaluates the impact message has on the memory, (Morley, 2007).

However, what is important for companies; stimulate the desire of potential customers to buy their products. Therefore, in this study will be carried out on Goldiran products, advertising effectiveness to create the willingness of customers to purchase the company's products is done.

The researchers also believe that the brand image related to factors beyond the physical aspects of product and is built from a combination of product physical reality and emotional and personal beliefs arise about it that this issue is concerned with how a person familiar with the product or brand. Because the customer between different brands for buying a product, select what has on its mind from a brand, not necessarily an accurate and complete comparison between brands available. Therefore, create the perfect image of a brand in customers' mind in selecting and deciding to choose one to buy can be effective (Dyndar farkush and Hydarbiegy, 1390).

According to what was said; the study aims to first, which one of Goldiran company advertising tools is more effective? Secondly, due to the fact that in this study the efficacy of research has been operating with two concept of brand equity and brand image, it turns out that what is advertising effect on willingness customers to purchase Goldiran products?

\section{Literature review}

\section{Review of concepts and theories Advertising effectiveness}

Marketing communication is a two-way conversation between the company and potential and actual customers of product and brand (Tong, Alley, 2009). Promoting activities is the bridge between the buyer and the seller and has the role of creating awareness, persuasion and influencing on the consumer decisions (Trehan, 2007). Supremacy in today competitive world needs proper marketing strategies; however, complicated conditions of the market, the introduction of new information technologies, constant changes in competition condition and in the automotive industry market caused it cannot be easily decide on the type of marketing strategy. Several factors that can affect the choice of marketing strategy among them the behavior of competitors and customers willingness can be noted. The behavior of buyers is one of the key factors that can play an effective role in selecting marketing strategy (Nikookar et al., 1388).

Buyer behavior is one of the newest subjects in the marketing area and the first book on the subject was written in 1960; however, records on this subject can be seen among which we can 
mention marketers using of Freud's ideas in the 1950s (Golchinfar, Bakhtiari, 1385). The buyer psychology in the 1980s was also discussed that in management literature known as buyer behavior. J.C Mowen, L. G Schiff man and M.R. Solomon have recently written significant works on buyer behavior (Asadi, 1379). Willkie and Solomon had defined buyer behavior in this way: physical, emotional, and mental activities that people are doing while select, purchase, use and dispose goods and services in order to satisfy their needs and desires. However, in another definition buyer behavior refers to a set of interlocking actions and deeds that the consumer does to choose goods or services, buy and use it (Iranmanesh, 1382). As well as, Thomas defined buying behavior in this way: a set of activities that are directly done in order to buy, use and disposal of goods and services (Assuel, 1995). From the moment that the person recognizes the need for goods or services until he or she buys and consumes it; a process of continuous operation is done which say it decision making process to buy (Blacwel et al., 2001).

One of the most important theories in the study of business is people's attitudes towards the ads. An attitude toward advertising is defined as: fields for response to a particular advertising stimulus in desirable or undesirable way in a special display position. Attitudes that are shaped toward advertising are effective on consumer attitudes toward the brand and also the purchase aim (Lord, 1995). If the final goal of advertising has been creating positive attitude toward advertising and brand, increasing the likelihood of purchase or a positive emotional response to an ad can be used as the best indicator of evaluating the effectiveness of advertising (Brown, Stymene, 1992).

\section{Brand}

Brand concept was also defined in the nineteenth century with the advent of Packaging industry. According to some statements, Pears soap was the first registered brand. The first definition for brand advertising was introduced about 1900 by James Walter Thompson which today has turned into the definition of branding. Very early, big companies also invented advertising slogans which were seen and heard in radio and the first television ads. In 1940, customers recognized the concept of social, psychological, anthropological and their relationship with brands and this led to manufacturers recognize other brand values and the need to take advantage of them and therefore so far, researchers paid attention to several concepts such as brand image, brand association, brand equity, brand loyalty and ... (Ghouchani et al., 1392).

Measuring brand equity requires consideration of several criteria along a number of different dimensions. Measures that are most effective in evaluating brand equity of products and market are as follows (Simon, 2006).

Brand management is the application of marketing techniques to a specific product or product line. Brand management tries to increase value for customers and ultimately, increase sales volume. Brand management is a tool to increase the desired quality of the customer and increase buying and building loyalty in customers. One of the major advantages of brand management for the company is that it can add to the price of goods and services in certain markets, without the loss of customers. In fact, brand management is a tool to differentiation (Borehan, 2010).

\section{Research Background}

Ghouchani et al., (1392) in a study examined the effect of media advertising as a marketing strategy on the behavior of passenger car buyers. The obtained results indicate that a variety of advertising such as visual, audio and written has effects on the behavior of passenger car buyers and their impact on the behavior of buyers had different priorities. Based on the results 
obtained, managers have been advised to dedicate each kind of advertisements with appropriate content to the relevant market and avoid this notion that some form of advertising does not work in this industry. Dehghani and Tomer (2015) study the impact of Facebook advertising effectiveness on the willingness of customers to purchase. This study was conducted among university graduates in Cyprus. The research was quantitative and the research strategy was descriptive, survey type. The questionnaire of this study was researcher made. The results of this study which was performed with the help of average comparing test of a community showed that the advertising effectiveness had a significant impact on brand image and brand equity. As well as, the brand image and brand equity had significant impact on customer's willingness to buy.

Varadrajan and Yadav (2013) in an article entitled "Marketing strategy in a virtual environment" study the relationship between advertising and the Internet. The results indicate that advertisements which were the most effective and efficient way to create willingness in people to consume a particular commodity at one time, today due to their growth and development have been threatened and on the other hand, Internet advertising due to lack of confidence in the community had not been succeeding in creating a position in many communities as an affective factor in the minds of customers.

Cohen et al (2014) in their study concluded that the impact of television on children's eating habits were usually justified based on the pattern of stimulus - response (conditioning). This means that the more minutes or hours watching ads (stimulus), it is more likely the person request and eats the advertised food (response).

\section{Theoretical framework of research}

In general, advertising has been evaluated using various tools and the researches in this area can be divided into two categories: quantitative and qualitative. In the first category, the effects of advertising on variables such as sales and profits are evaluated and in the second category, factors such as brand, consumer behavior, attitudes and consumer willingness have been studied. In this research, based on Dehghani and Tumer model (2015), the researcher has defined the goal of advertising creating brand image and brand equity. On the other hand, it can be claimed that advertising is effective, if cause willingness and stimulates potential customers to buy the company product. Therefore, in this study in addition to evaluate the effects of advertising on brand image and brand equity, the effect of advertising on brand image and brand equity on willingness of customers to purchase the Goldiran company's products are also addressed.

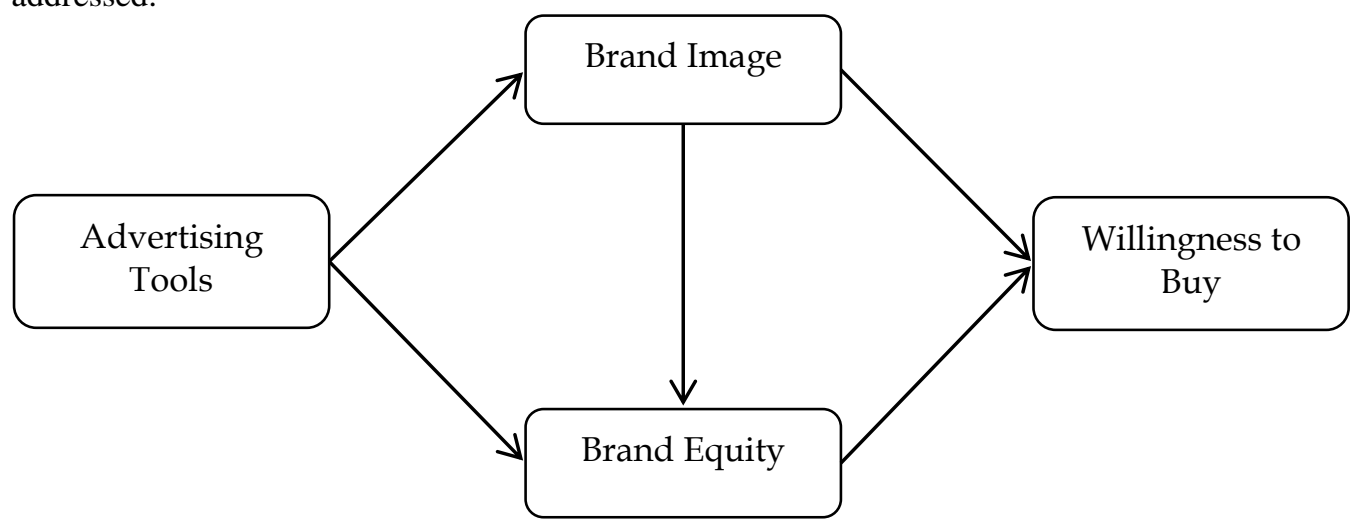

Fig. 1. The conceptual model of Dehghani and Tumer (2015) 


\section{Research Hypothesis}

Brand equity, as a mediator variable has a significant effect on the relationship between the advertising effectiveness and customer willingness to buy Goldyiran products.

Brand image, as a mediator variable has a significant effect on the relationship between the advertising effectiveness and customer willingness to buy Goldyiran products.

Advertising tools (in separation) has a significant effect on brand image.

Advertising tools (in separation) has a significant effect on brand equity.

Brand image has a significant effect on the willingness of consumers to purchase.

Brand equity has a significant effect on the willingness of consumers to purchase.

Brand image has a significant effect on the brand equity.

\section{Research Methodology}

This research is a quantitative research type because hypotheses will be examined using data from questionnaires and statistical tests. Researchers also consider three overall directions such as fundamental, developmental and applicable for a research which this is an applied research type due to the aim; because the results of this study offered to the Goldiran Company and lead them to have a better understanding of consumer behavior. Also, given that the researcher described the situation of the research variables without altering the research, the research strategy is descriptive. On the other hand, considering that researcher used a sample for evaluating hypothesis and generalize its result to all community, so that descriptive strategy in this research is a survey type. In addition, in this study, the effect of independent variable (s) on the dependent variable is analyzed. Therefore, the research strategy is cause and effect, therefore it can be claimed that the research strategy is divided into two parts of descriptivesurvey and cause-effect.

\section{Community and the statistical sample}

The population of this research includes buyers of Goldiran Company products in Tehran.

Due to the impossibility of reviewing all the statistical population, some samples were selected using sampling formula of Cochran unlimited society. According to the following formula, the sample size is:

$$
n=\frac{\left(Z_{\propto}\right)^{2} \times p q}{d^{2}}
$$

The statistical sample is consisting of 384 people. Given the extent of Tehran and economic, social and ... differences between different areas of Tehran, the researcher used cluster random sampling method to select the sample group.for this purpose, the researcher divided the city of Tehran to five sections of the North, South, Central, West and East and the questionnaire randomly distributed in each section (in sales representatives LG products).

\section{Methods and tools for data collection}

The researcher among the methods of collecting information used the library method and collected the theoretical foundations with the help of articles, journals, reliable web sites and scientific books and to test research hypotheses used field method and the questionnaire for collecting required data. 


\section{Questionnaire}

Danaeefard and et al., (1389) know questionnaire a pre-established collection that respondents select their answers within a certain range of options. To gather the desired data to test hypotheses as well as measuring customer opinions, the researcher used two questionnaires of Gafari (1393) and Boyle et al., (2013). In total, the questionnaire is composed of two parts of general questions and specific questions.

Table 1. Structure of the questionnaire

\begin{tabular}{|c|c|c||}
\hline Dimensions & Questions & Reference \\
\hline Advertising effectiveness & $1-5$ & Jafari (1393) \\
\hline Brand image & $6-9$ & Boyle et al. (2013) \\
\hline Brand equity & $10-13$ & Boyle et al. (2013) \\
\hline Customer willingness to buy & $14-19$ & Jafari (1393) \\
\hline
\end{tabular}

\section{Validity of the questionnaire}

Validity means that measuring tool can measure the desired features and characteristics (khaki, 1382). The concept of validity answers this question that measuring tool to what extent measure the desired characteristic? Considering that questionnaire is used in this study, the researcher to ensure the accuracy of transfer right questions tried to evaluate the validity of the questionnaire with the help of content validity. In this way, the questionnaire was given to the eleven experts, including Supervisor and asked them about each question and its ability to assess the related purpose of the study and due to the expert's opinions, minor adjustments have been done in the questionnaire and finally the Validity of questionnaire was confirmed by them.

\section{Reliability of the questionnaire}

The reliability of a measure shows logic stability of responses in measuring tool and helps to properly evaluate a measure. Stability, pointing out that if a test measures individual intelligence, its results has been the same on the individual at different times. "The ability is" a measure to maintain stability over time (despite the uncontrollable condition of the test and the status of the respondents) and an indicator of its stability and low vulnerability to changes. This ability indicates the appropriateness of measurement tool because each time measurement take place, the same results will be obtained. Basically, humanities researchers using Cronbach's alpha to assess the reliability of their questionnaire. For this purpose, the researcher distributed 30 questionnaires and using this technique, the following results were obtained.

Table 2. The reliability of research variables

\begin{tabular}{||c|c||}
\hline \hline Dimensions & Cronbach's alpha coefficient \\
\hline Advertising effectiveness & 0.84 \\
\hline Brand image & 0.89 \\
\hline Brand equity & 0.94 \\
\hline Customer willingness to buy & 0.84 \\
\hline
\end{tabular}

According to Cronbach's alpha amount obtained for each variable, research questionnaire has the enough reliability. 


\section{Research Findings}

\section{Analysis confirmatory factor of model variables}

The researchers first examined the confirmatory factor analysis of the independent variable; then dependent variable and the mediator confirmatory factor analysis are examined.

\section{Analysis confirmatory factor of independent variable}

Because in this study the advertising effectiveness variable is as the independent variable which is without dimension, so its factor analysis should be done in one step.

In one step factor analysis, the relationship between the questions and variable is called factor loadings. All factor loadings should be greater than 5.0 to be accepted. In the above figure, all factor loadings are greater than 0.5 , so it can be said that advertising effectiveness variable is measured well by questions.

Being a significance coefficient means that the number should be greater than 1.96 or smaller than -1.96. In the above figure, all significant coefficients are greater than 1.96 which represents confirming the confirmatory factor analysis. Therefore, we can say that this variable is measured well by its questions.

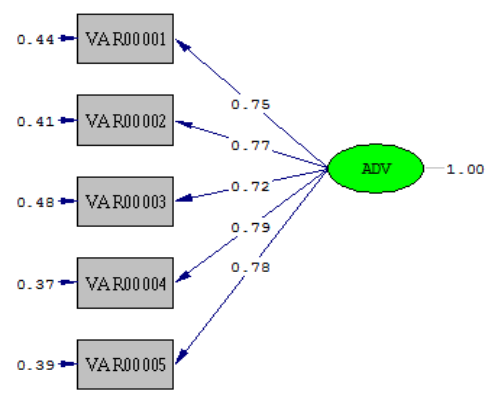

Chi-Square $=38.37, \mathrm{df}=5, \mathrm{P}-\mathrm{value}=0.00000, \mathrm{RMSEA}=0.132$

Fig. 2. Confirmatory factor analysis of independent variable in standard estimation mode

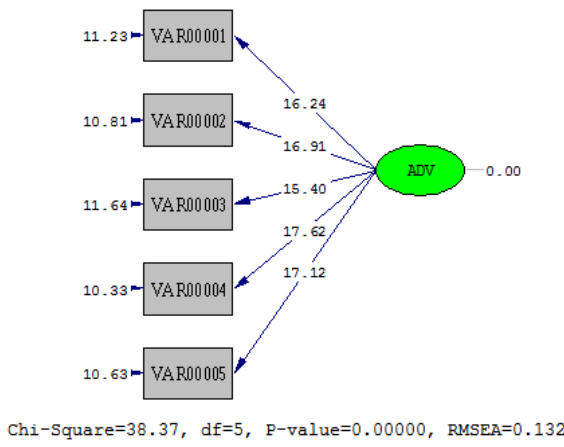

Fig. 3. Confirmatory factor analysis of independent variable in significant coefficients mode

\section{Confirmatory factor analysis of brand image mediator variable}

As mentioned, after confirmatory factor analysis of the independent variable, it turns to confirmatory factor analysis of brand image mediator variable that because in this research has not any dimension and directly have been measured with questions, then it is one-stage variable and just only has one factor analysis.

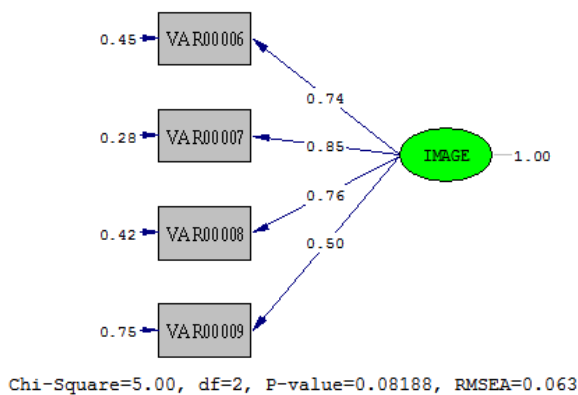

Fig. 4. Confirmatory factor analysis of brand image mediator variable in standard estimation mode

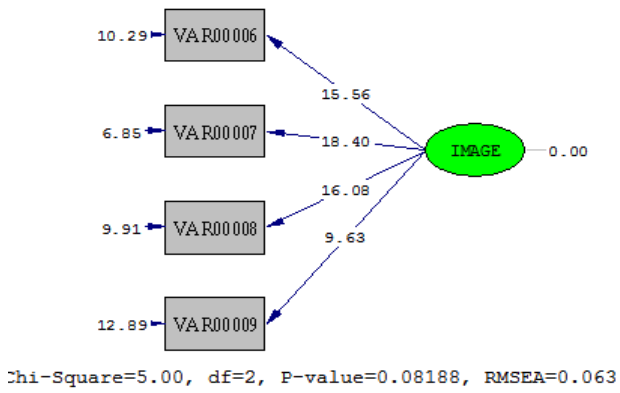

Fig. 5. Confirmatory factor analysis of brand image mediator variable in significant coefficients mode

Due to this fact that all factor loadings are higher than 0.5 , it can be claimed that the questions measured well brand image variable. 
Factor loadings between mediator variable and questions in a significant coefficients mode are all have relatively high significant coefficient (greater than 1.96) and therefore confirm a confirmatory factor analysis of this variable. In other words, questions have been able to measure well brand image mediator variable.

\section{Confirmatory factor analysis of brand equity mediator variable}

After investigating confirmatory factor analysis of brand image mediator variable, it turns to confirmatory factor analysis of brand equity mediator variable that because in this research has not any dimension and directly have been measured with questions, then it is one-stage variable and just only has one factor analysis.

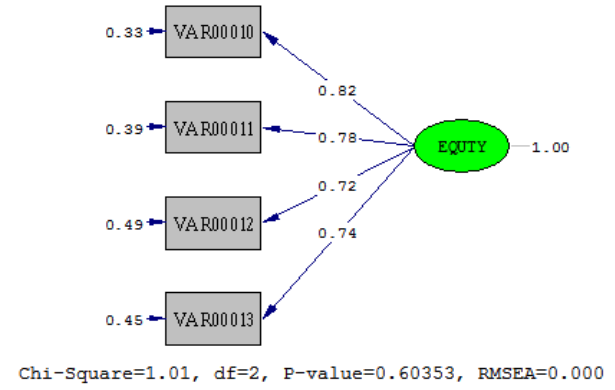

Fig. 6. Confirmatory factor analysis of brand equity mediator variable in standard estimation mode

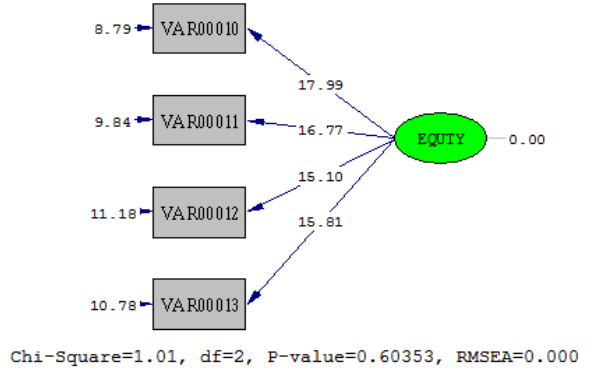

Fig. 7. Confirmatory factor analysis of brand equity mediator variable in significant coefficients mode

Due to this fact that all factor loadings are higher than 0.5 , it can be claimed that the questions measured well brand equity variable.

Factor loadings between mediator variable and questions in a significant coefficients mode are all have relatively high significant coefficient (greater than 1.96) and therefore confirm a confirmatory factor analysis of this variable. In other words, questions have been able to measure well brand equity mediator variable.

\section{Confirmatory factor analysis of dependent variable}

After investigating confirmatory factor analysis of independent and mediator variables, it turns to confirmatory factor analysis of dependent variable that because in this research has not any dimension and directly have been measured with questions, then it is one-stage variable and just only has one factor analysis.

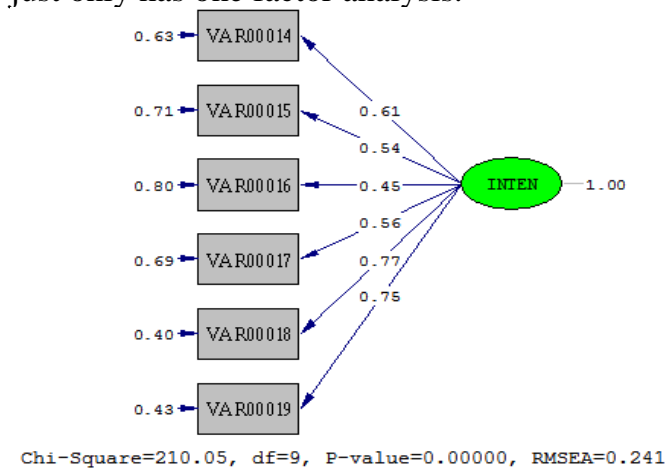

Fig. 8. Confirmatory factor analysis of dependent variable in standard estimation mode

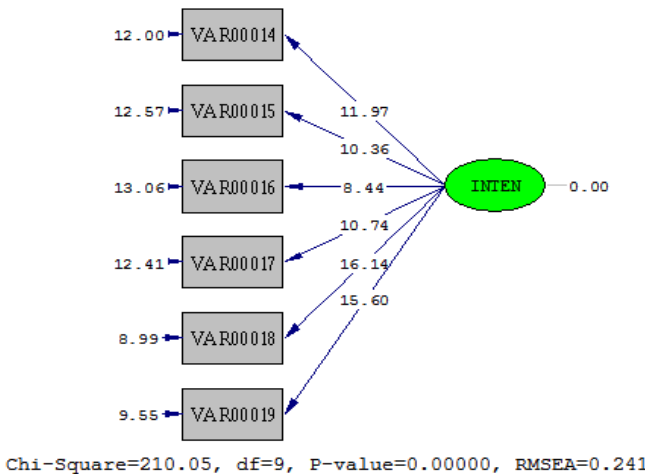

Fig. 9. Confirmatory factor analysis of dependent variable in significant coefficients mode 
Due to this fact that all factor loadings are higher than 0.5 , it can be claimed that the questions measured well dependent variable.

Factor loadings between mediator variable and questions in a significant coefficients mode are all have relatively high significant coefficient (greater than 1.96) and therefore confirm a confirmatory factor analysis of this variable. In other words, questions have been able to measure well dependent variable.

\section{Evaluation Structural equations model}

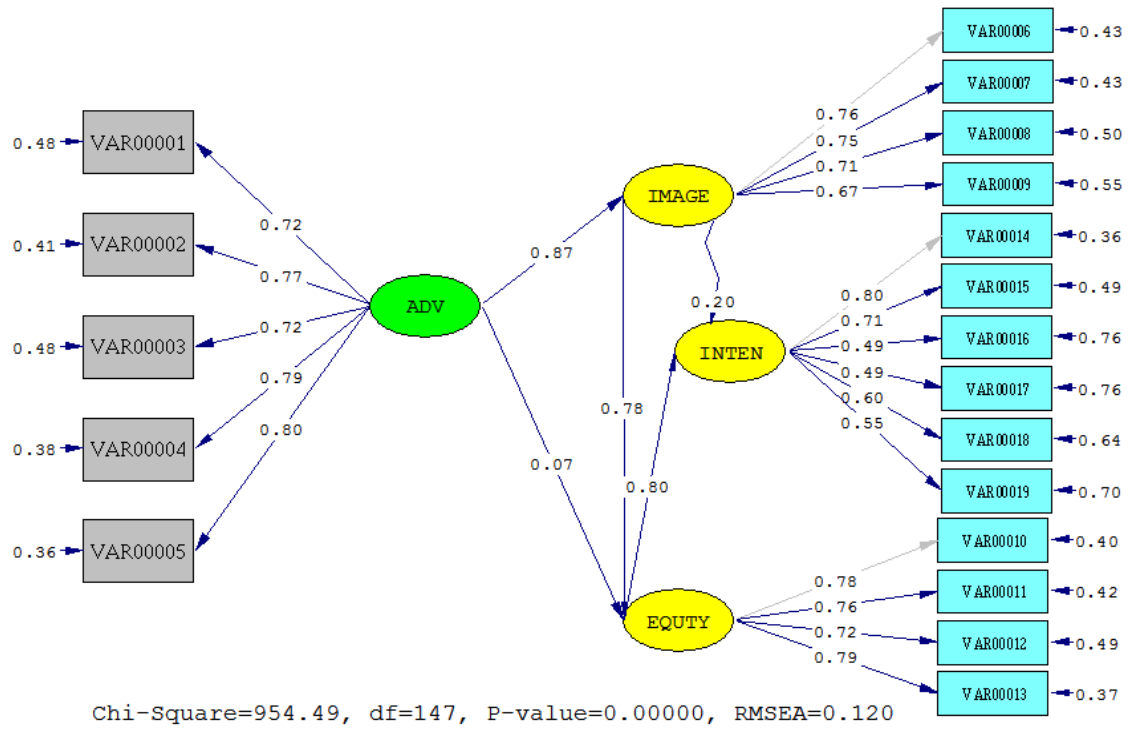

Fig. 10. Significant model of research hypotheses in the standard estimation mode

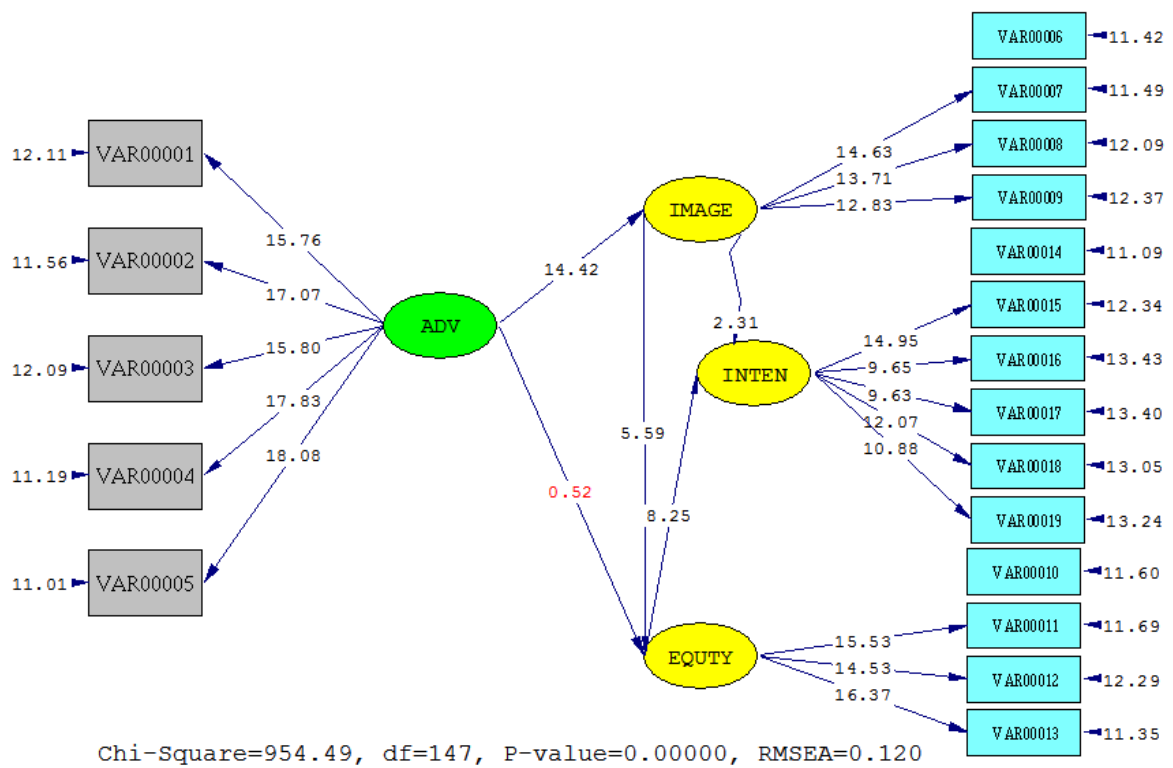

Fig. 11. Significant model of research hypotheses in significant coefficients mode 


\section{Evaluating the main research hypotheses}

Primary and secondary hypotheses were evaluated in the following table:

Table 3. The results of structural equation modeling analysis: the first main hypothesis of the study

\begin{tabular}{|c|c|c|c|c|c|c|}
\hline Hypothesis & Direction & $\begin{array}{l}\text { Independent } \\
\text { variable }\end{array}$ & $\begin{array}{l}\text { Dependent } \\
\text { variable }\end{array}$ & $\begin{array}{l}\text { Standard } \\
\text { coefficient }\end{array}$ & $\begin{array}{c}\mathrm{T}- \\
\text { value }\end{array}$ & Test result \\
\hline \multirow{3}{*}{ Main 1} & Path 1 & $\begin{array}{c}\text { Advertising } \\
\text { effectiveness }\end{array}$ & Brand Equity & 0.07 & 0.52 & Confirmed \\
\hline & Path 2 & Brand Equity & $\begin{array}{l}\text { Willingness to } \\
\text { buy }\end{array}$ & 0.8 & 8.25 & Rejected \\
\hline & $\begin{array}{l}\text { Brand } \\
\text { Equity }\end{array}$ & $\begin{array}{c}\text { Advertising } \\
\text { effectiveness }\end{array}$ & $\begin{array}{l}\text { Willingness to } \\
\text { buy }\end{array}$ & $\begin{array}{c}0.056=0.8 \times \\
0.07\end{array}$ & -- & Confirmed \\
\hline \multirow{3}{*}{ Main 2} & Path 1 & $\begin{array}{l}\text { Advertising } \\
\text { effectiveness }\end{array}$ & Brand Image & 0.87 & 14.42 & Rejected \\
\hline & Path 2 & Brand Image & $\begin{array}{c}\text { Willingness to } \\
\text { buy }\end{array}$ & 0.2 & 2.31 & Rejected \\
\hline & $\begin{array}{l}\text { Brand } \\
\text { Image }\end{array}$ & $\begin{array}{c}\text { Advertising } \\
\text { effectiveness }\end{array}$ & $\begin{array}{l}\text { Willingness to } \\
\text { buy }\end{array}$ & $\begin{array}{c}0.17=0.2 \times \\
0.87\end{array}$ & -- & Confirmed \\
\hline Sub 1 & - & $\begin{array}{c}\text { Advertising } \\
\text { effectiveness }\end{array}$ & Brand Equity & 0.07 & 0.52 & Confirmed \\
\hline Sub 2 & - & $\begin{array}{l}\text { Advertising } \\
\text { effectiveness }\end{array}$ & Brand Image & 0.87 & 14.42 & Rejected \\
\hline Sub 3 & - & Brand Image & $\begin{array}{l}\text { Willingness to } \\
\text { buy }\end{array}$ & 0.2 & 2.31 & Rejected \\
\hline Sub 4 & - & Brand Equity & $\begin{array}{c}\text { Willingness to } \\
\text { buy }\end{array}$ & 0.8 & 8.25 & Rejected \\
\hline Sub 5 & - & Brand Image & Brand Equity & 0.78 & 5.59 & Rejected \\
\hline
\end{tabular}

\section{Discussion and conclusion}

\section{Discussion}

In the first hypothesis of this study, the effect of brand equity on the relationship between advertising effectiveness and the customer's willingness to buy Goldiran products were examined. This research in studies such as Ghouchani and et al., (1392), Dindarfarkoosh and Heidarbiegy (1390), Shah Mohammadi and Ahmad Oskooi (1390), Cohen et al., (2014), Pine and Nash (2009), Pita and Flawler (2013), Varadarjan and Yadav (2013), Dehghani and Tomer (2015) has been directly or indirectly noted that was found by comparing the results of these studies with the present study. The obtained result showed that advertising had effect on the behavior of passenger car buyers that compared to the results of the present study; it was found that the results of two studies are not consistent with each other. In fact, advertising on Goldiran products through two mediator variables did not cause stimulate demand and the willingness of individual to purchase. The results of Dehghani and Tomer (2015) on the effectiveness of Facebook ads on the willingness of customers to buy revealed that brand equity mediator is effective on this relationship that is contrary to the present results.

In the second hypothesis of this study, the effect of brand image on the relationship between advertising effectiveness and the customer's willingness to buy Goldiran products were examined. This research had been done in studies such as Dindarfarkoosh and Heidarbiegy (1390).

In this study, which examined the impact of commercial advertising Persian-language satellite networks on audience attitude and their actions to purchase, it was found that advertising had a significant effect on the audience attitude. This can be due to the fact that in principle commercial advertising of Persian-language satellite channels promote products that 
pay less in the official TV of the country; therefore, there is less possibility of comparison in mind of audience and so he or she may create deeper and more effective image about that product in his, her mind.

In the first secondary hypothesis of this study, the effect of advertising effectiveness on brand equity of Goldiran products was examined. This research had been done in studies such as Mira and Karim (1391) (1390). In that study, the effect of media and non-media advertising on brand equity, name and logo of Pars Khazar was discussed. The results showed that commercial advertisements have the greatest impact on brand equity. This may be because there is no competitor company for Pars Khazar in public media ad (to the same number of Pars Khazar Company), therefore this advertisement reflects the strength and credibility of the company. While competitors such as LG make extensive advertising, therefore advertising brand equity simply does not promote the company's brand.

In the second secondary hypothesis of this study, the effect of advertising effectiveness on brand image of Goldiran products was examined. The results of structural equation model in LESREL software suggests that the effectiveness of advertising on brand image of of Goldiran products had a positive, direct and significant (0.87) effect. The results Dehghani and Tomer research (2015) showed that advertising has a significant impact on brand image that the results of both studies are parallel to each other.

In the third secondary hypothesis of this study, the effect of brand image on willingness to buy Goldiran products was examined. This research also was conducted on studies such as Varadarjan and Yadav (2013) and it was found that due to the influx of Internet advertising and a lack of confidence to these ads, there is no proper image in the customer's mind from Internet advertising. This is partly consistent with the results of the present study that may be due to the influx of deceptive business advertising and loss of public confidence to the business advertising.

In the fourth secondary hypothesis of this study, the effect of brand equity on willingness to buy Goldiran products was examined. Although considering the first secondary hypothesis, it was turned out that advertising did not lead to brand equity for the company's products; However, brand equity (be obtained any other way for the brand of this company) tends to significantly increase the customer's willingness to buy.

In the fifth secondary hypothesis of this study, the effect of brand image on brand equity of Goldiran products was examined. The results of Dehghani and Tomer (2015) were also in line with the results of this study.

\section{Research suggestions}

According to the first and second hypothesis of the study, it was found that the company's advertisement through brand equity and brand image does not lead to customers' willingness to buy; so that, the researcher suggests the managers of these companies if their purpose of advertising is to create a willingness to buy through these two concepts, have fundamental review of the concept, appearance, text, songs, etc. of their ads.

According to the first secondary hypothesis which demonstrated the company's advertising does not lead to increase brand equity; so that, the researcher suggests the managers of these companies to emphasize in their advertisement on services and unique features that other competitors does not. (This becomes important because according to the fourth secondary hypothesis; if there is any brand equity, tend to buy Goldiran products increases).

According to the first secondary hypothesis which demonstrated the company's advertising does not lead to increase brand equity; so that, the researcher suggests the managers of these companies to emphasize in their advertisement on services and unique features that other competitors does not. 
According to the third and fourth secondary hypothesis that it was found the brand image and brand equity has effect on willingness to buy Goldiran products, so that, the researcher suggests the managers of these companies to work more on the development of company's brand.

\section{REFERENCES}

1. Aaker, D.A. (1996). Measuring brand equity across products and markets. California management review, 38(3), 102-120.

2. Asadi, K. (2000). The effect of hygiene detergent commercials on buyer behavior, MSc thesis, Business Administration, Shahid Beheshti University.

3. Assuel, H. (1995). Consumer behavior and marketing action, In Lain, Hong, Lu, Duoc and Tu. Li(eds.), Kristianstand University the Department of Business Studies.

4. Buil, I., Martinez, E., Chernatony, L. (2013). The influence of brand equity on consumer responses, Vol. 30, No. 1, pp: 62-74.

5. Campbell, E., Wright, T. (2008). «Shut-up I don't care: understanding the role of relevance and interactivity on customer attitudes toward repetitive online advertising», Journal of Electronic Commerce Research, Vol 19, No1, pp. 62-74.

6. Coon, K.A., Goldberg, J., Rogers, B.L., Tucker, K. L. (2014). «Relationships between Use of Television during Meals and Children's Food Consumption Patterns Pediatrics». Vol 1, No 107, PP: 1-17.

7. Dehghani, M., Tumer, M. (2015). A research on effectiveness of Facebook advertising on enhancing purchase intention of consumers. Computers in Human Behavior, Vol. 49. pp: 597600.

8. Esmi, R., Sadipour, E., Asadzadeh, H. (2010). The relationship between watching TV ads and consumption pattern in children and adolescents in Tehran, Journal of Communication Research. (1) (61). 117-93.

9. Gil, R., Brave Fraj, A., Martinez Salinas, E. (2007). «Family as a source of consumer-based brand equity», Journal of Product \& Brand Management, Vol. 16, No. 3, pp. 188-199.

10. Golchinfar, Sh., Bakhtiari, A. (2006). Marketing Clinic, Journal of Tadbir, No. 170, pp. 110115 .

11. Hosseini Anjadali, M. (2000). Evaluation of the impact theory TV ads on children's behavior and attitude. Tehran, IRIB Research Center. (48).

12. Iranmanesh, M. (2003). Understanding how consumer behavior in the market of health care products - cosmetics and detergents, Eighth International Conference on Industrial Health \& Beauty, Tehran, 78-74.

13. Jafari, Z. (2014). Compare the effectiveness of advertising external network and internal network Persian language in Iran (Case Study: Compare and market network TMTV). Master of Science thesis Karshasy communication. Islamic Azad University. Science research.

14. Khaki, Gh. (2003). The method of approach to the dissertation, Tehran, Baztab publications, Second Edition.

15. Morley, B (2007). «National Community Survey of TV Food Advertising to Children». Cancer Control Research Institute, The Cancer Council Victoria.

16. Nash, A.S., Pine, K.J., Messer, D.J. (2009). Television alcohol advertising: do children really mean what they say? British Journal of Developmental Psychology. 27, pp: 85-104

\section{Article history:}

- $\quad$ Received 10 September 2017

- $\quad$ Accepted 24 November 2017 